\title{
The Subgenus Scaptia (Lepmia) Fairchild: Redescription of Females and Description of a Male (Diptera: Tabanidae: Pangoniinae)
}

\author{
S Coscarón/ ${ }^{+}$, P lide*
}

Facultad de Ciencias Naturales y Museo de La Plata, Paseo del Bosque s/n, 1900 La Plata, Argentina *Laboratório da Coleção Entomológica, Departamento de Entomología, Instituto Oswaldo Cruz-Fiocruz, Rio de Janeiro, RJ, Brasil

The subgenus Scaptia (Lepmia) Fairchild, known only from mountanous areas of Southeast of Brazil, is redescribed and illustrated. It is contrasted with similar species of Scaptia (Pseudoscione). It is more similar to the Australian Myioscaptia and Plinthina than to the other New World Scaptia subgenera.

Key words: horsefly - Scaptia (Lepmia) - taxonomy - Neotropical region

The genus Scaptia is represented in the Neotropical region by 4 subgenera: 3 of them recently revised: Pseudoscione (16 sp., Wilkerson \& Coscarón 1984), Scaptia (10 sp., Coscarón \& Wilkerson 1985), Pseudomelpia (1 sp., Coscarón \& Gonzalez 2001); only Lepmia (2 species) remains unrevised. The species are found in the Southern Cone of South America, especially in the Neantarctic subregion. Genus Scaptia is also present in the Australian region with subgenera Pseudoscione (26 sp.), Scaptia (28 sp.), Myoscaptia (7 sp.), Plinthina (7 sp.), and Palimmecomyia (7 sp.) (Mackerras 1960).

The subgenus Lepmia Fairchild 1969 presently contains 2 species from Southeast of Brazil. As indicated by the author, the species are characterized by "a stout and heavely sclerotized proboscis with apices somewhat bulbous". As with other Scaptia species, subgenus Lepmia are stout, moderately sized, with an inflated subshiny abdomen. Lepmia is also characterized by wide maxillary palp, front elongated and divergent below, wing faintly brown fumose with a yellowish hue acentuated on anterior border, genital cerci wider than long, with distal border concave, genital fork narrower basally, gonapophysis wider than long, and male with gradually accuminated gonostylus with blunt apex.

Lepmia shows great similarity with the other Scaptia subgenera (Coscarón \& González 2001).

\section{MATERIALS AND METHODS}

The specimens studied were collected in the states of São Paulo and Rio de Janeiro and are deposited in the collections from Department of Entomology of Museu de Zoologia de São Paulo.

The study was made in accordance with the methodology of Coscarón and Gonzalez (2001).

\footnotetext{
${ }^{+}$Corresponding author. Fax: +54-221-425.7527. E-mail: sixtoco@museo.fcnym.unlp.edu.ar

Received 26 December 2002

Acepted 10 July 2003
}

\section{DESCRIPTIONS \\ Scaptia (Lepmia) molesta (Wiedemann) (redescription)}

Scaptia (Lepmia) molesta: Fairchild 1971: 16, Coscarón and Papavero, 1993: 62, fig. 26 a-c, Fairchild and Burger 1994: 38

Pangonia molesta Wiedemann 1828: 91, Enderlein 1925: 271, Kröber, 1930: 189

Pangonia exeuns Walker 1850: 12

Diatomineura exeuns: Lutz 1909: 653 pl. 2, fig. 31

Diatomineura molesta: Lutz 1909: 654 pl. 2, fig. 32

A median sized yellowish brown fumose winged species with wide subtrapezoidal palp (Figs 2-3).

Female: body length 14.3-15.5 mm, wing: length 13-13.5 $\mathrm{mm}$, width 4-4.7 mm. Eyes blackish, bluish iridescent (relaxed), with yellowish pilosity. Proboscis shiny black; flagellum and palpus light reddish brown with yellowish brown pilosity. Front, subcallus, antennal scape and pedicel, and frontoclypeus, brown pollinose with concolorous hairs, changing to blackish depending on incidence of light. Occiput and posterior head area light gray pollinose with yellowish brown hairs. Front divergent below, ocellar tubercle prominent with 3 well developed ocelli, front height $1.7-1.8 \mathrm{~mm}$, width: at base $0.6 \mathrm{~mm}$, at vertex $0.4 \mathrm{~mm}$; frontal index $=3-3.1$; frontal basal divergence =1.3-1.4. Basal article of flagellum a little narrower than scape diameter. Frontoclypeus length about equal to front height. Proboscis a little shorter than head height (Fig. 1). Scutum and metanotum light brown with gray pollinosity and yellowish brown hairs; pleura and legs yellowish brown pollinose. Wing slightly brownish fumose; wing veins light brown with dark hairs. No appendix on $\left(\mathrm{R}_{4+5}\right)$. Halter light grayish brown. Abdomen bright reddish brown darkened on posterior half of segments, with pilosity yellowish to black depending on incidence of light, and becoming darker posteriorly. Cercus wider than high, truncate with small median depression apically, IX tergite with long hairs (Fig. 4).

Male: unknown.

Material examined: Brazil: São Paulo, São Sebastião Island, 12-IV-63, col. Urban (on human) 1 female; Serra Negra, V-45, col. Lima: 1 female. 
Geographic distribution: Southeast Brazil: Minas Gerais, Rio de Janeiro, São Paulo.

Discussion: the closest species is seminigra which has a longer palp, lighter scutum and abdomen, and is a little shorter. Our material is in agreement with the Wiedemann (1828) description, based on the molesta original description and the redescriptions of Lutz (1909) and Kröber (1930) of Scaptia exeuns (Walker), we accept exeuns as a synonym of molesta.

Scaptia (Lepmia) seminigra (Ricardo) (redescription of the female and description of the male) Scaptia (Lepmia) seminigra: Fairchild 1969: 203, 1971: 16, Fairchild and Burger 1994: 38
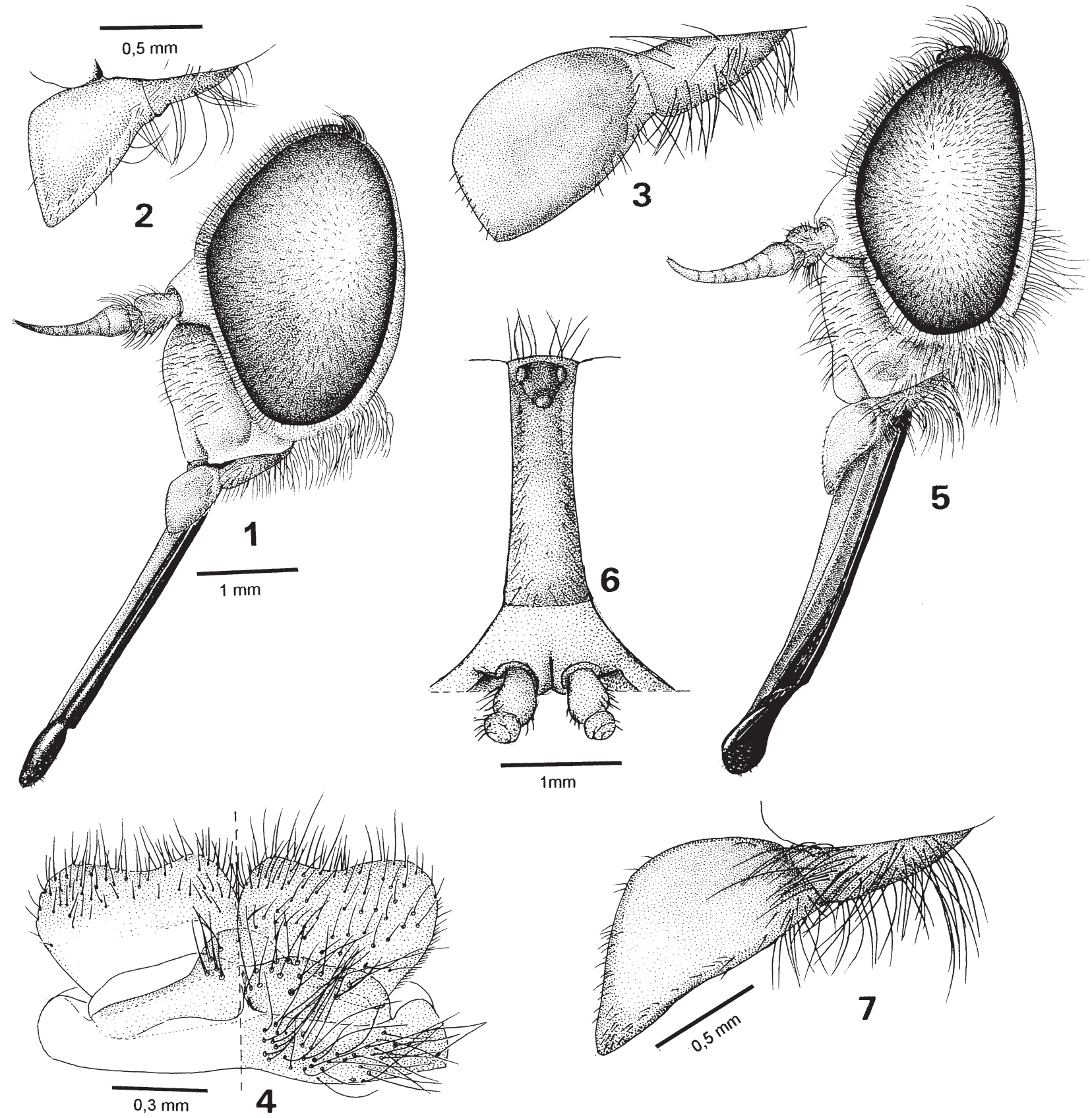

Diatomineura seminigra Ricardo 1902: 432

Melpia ferruginea Enderlein 1925: 277, Fairchild 1966: 10, fig. 14

Parosca ferruginea: Kröber 1930: 188-189, fig. 31

A medium to large yellowish brown species with proboscis shiny blackish, labella wholly sclerotized, scutum and abdomen yellowish brown, and wing hyaline but slightly infuscated yellowish brown especially on the costal border. Female: body length $13-13.5 \mathrm{~mm}$, wing length $12-13 \mathrm{~mm}$, width 4.1-4.3 mm. Eyes greenish black iridescent (relaxed), with yellowish brown pilosity; front, subcallus, frontoclypeus, occiput, antenna, palp, yellowish light brown with concolorous pilosity; occiput with light gray pollinosity. Beard yellowish brown to dark brown

Scaptia (Lepmia) molesta female - Fig. 1: head. Figs 2-3: maxillary palp. Fig. 4: IX-X tergites and cerci. S. (L.) seminigra female - Fig. 5: head. Fig. 6: front. Fig. 7: maxillary palp (similar scale: 1, 5; 2, 3) 
depending on incidence of light. Front narrow, divergent below, ocellar tubercle slightly elevated, with 3 well developed ocelli (Fig. 6); front height 1.8-1.9 mm, width: at base $0.6-0.7 \mathrm{~mm}$, at vertex $0.4-0.5 \mathrm{~mm}$; frontal index $2.7-3$; frontal basal divergence 1.2-1.3; antenna with pedicel narrower than scape and basal segment of flagellum. Palp wide, but narrower apically with anterobasal and posterior rim slightly elevated (Fig. 7). Proboscis a little longer than

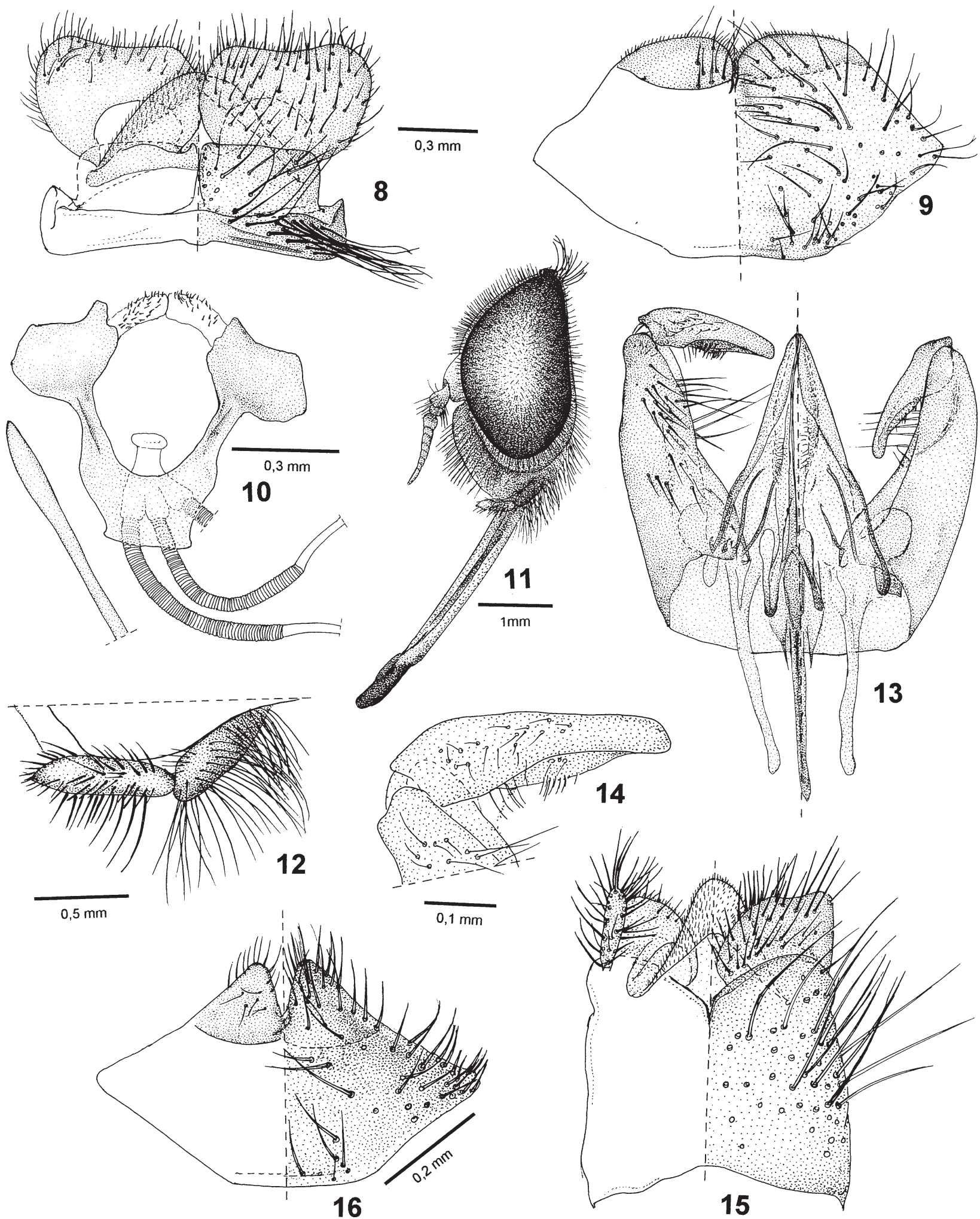

Scaptia (Lepmia) seminigra, 8-10 female - Fig. 8: IX-X tergites and cerci. Fig. 9: VIII sternite and gonapophysis. Fig. 10: genital fork and spermatheca; 11-15 male - Fig. 11: head. Fig. 12: maxillary palp. Fig. 13: gonocoxite, basistyli, dististyli and aedeagus. Fig. 14: dististyle. Fig. 15: epandrium, ventral plate of proctiger and cerci. Fig. 16: S. (Pseudoscione) hibernus female: VIII sternite and gonapophysis (similar scale: 8,$9 ; 10,13,15$ ) 
head height (Fig. 5), with labella bulbous, very sclerotized. Scutum with hairs varying from yellowish golden to copper colored. Pleura, coxae and legs light yellowish brown; pleura with light gray pollinosity. Wing veins yellowish brown with hairs light brownish to blackish depending on light incidence. Fork and third vein $\left(\mathrm{R}_{4+5}\right)$ without appendix. Abdomen subshiny, darkened on posterior tergites, hairs yellowish golden to copper colored. Cercus wide with posterior border concave, IX tergite with abundant, black elongate hairs (Fig. 8). VIII sternite two times wider than long and gonapophysis broad with convex border (Fig. 9). Genital fork with narrow base and abundant microtrichiae on combs (Fig. 10).

Male: body length $11 \mathrm{~mm}$, wing: length $10.6 \mathrm{~mm}$, width $3.4-3.5 \mathrm{~mm}$. Color similar to female, but slightly paler on scutum and abdominal terga than some females. Black violaceous greenish eyes (relaxed) with a slightly longer hairs than female, as also are frontoclypeus and beard hairs. Upper central facets not well differentiated from smaller lower facets. Ocellar tubercle raised above level of eyes, with three distinct ocelli and long hairs. Antenna as female, scape with longer hairs. Palp elongated with apex bare laterally (Fig. 12). Proboscis longer than head height (Fig. 11). Gonocoxite a little wider than basistyle length; dististyle pointed distally with blunt apex; aedeagus robust (Figs 13-14); epandrium elongated, gradually concave basally, ventral plate of proctiger narrow and cerci subtrapezoidal (Fig. 15).

Material examined: Brazil, São Paulo, Salesópolis, Est. Biol. Boraceia, 850 m, 29-VIII-61, col. Rabello, 1 female; Caraguatatuba, Res. Flor. 7/14-VII-62, col. Exp. Dep. Zool.: 1 female; São Paulo, Capital, I-1935, col. Pessoa: 1 female. Rio de Janeiro, Distr. Federal, V-1938, col. Serv. Febre Amarela, M.E.S. Brazil; Angra dos Reis, Fazenda Japuhyba, VII-45, col. L.T.F.: 1 male.

Geographic distribution: Southeast Brazil: Minas Gerais, Espirito Santo, Rio de Janeiro, and São Paulo.

Discussion: our material is in agreement with the Ricardo's description, but body length is longer than his $(11 \mathrm{~mm})$. Specimens compared with the ferruginea holotype agree with it, and we are in accordance with Fairchild's (1966) comments; molesta is differentiated especially by the short palp. Kröber's ferruginea drawings show the front narrower basally and palp more elongated. Kröber (1934) also considered erroneously seminigra as a synonym of Fidena tabanipennis (Macquart).

Among the $S$. (Pseudoscione) species, the closest is $S$. (P.) hibernus Wilkerson \& Coscarón 1984. Differences in palp shape, and that hair color on the frontoclypeus, gena, beard and pleura are dark brown mixed with grayish yellow, permit differentiation; in addition, the VIII sternite shape with pointed gonapophysis and a deep separation between them (Fig. 16), plus the elongate cercus shape without a distal concavity, also help to differentiate these species.

The closest species to molesta and seminigra in the Neotropics are S. (Pseudoscione) hibernus (Southeast Brazil), and latipalpis and subulipalpis (South Chile) (Wilkerson \& Coscarón 1984).

It is possible to differentiate the Pseudoscione species by a relativelly shorter front, maxillary palp apically accuminated, emarginated, often with a central depressed area, the labella more elongated and not very sclerotized, and gonapophysis more accuminated.

In contrast, the Australian Myoscaptia and Plinthina species have, as does Melpia, the distal article of maxillary palp not accuminated, and female VIII sternite and gonapophysis wider with gradually rounded apical borders. This similarity is evidence of the close transantarctic relationship between the Scaptia faunas, with 2 Neotropical subgenera in common with Australia (S. (Scaptia) and S. (Pseudoscione), and another 3 subgenera endemic to each continent, all of them morphologically similar.

\section{ACKNOWLEDGEMENT}

To Professor Nelida Caligaris by the help in illustrations and genitalic dissections.

\section{REFERENCES}

Coscarón S, González C 2001. Posición sistemática y redescripción de Scaptia (Pseudomelpia) horrens Enderlein, 1925 (Diptera: Tabanidae: Pangoninae). Acta Entom Chilena 25: 31-40.

Coscarón S, Papavero N 1993. An Illustrated Manual for the Identificationn of the Neotropical Genera and Subgenera of Tabanidae (Diptera), Museu Paraense Emilio Goeldi, Coleção Emilie Snethlage, Belém, 150 pp.

Coscarón S, Wilkerson RC 1985. South American Scaptia (Scaptia) (Diptera: Tabanidae) with a key to the species of the Subgenus. MYIA 3: 277-298.

Enderlein G 1925. Studien an blutsaugenden Insekten. I. Grundlagen eines neuen Systems der Tabaniden. Mitt Zool Mus Berlin 11: 255-409.

Fairchild GB 1966. Notes on Neotropical Tabanidae. V. The species described by G. Enderlein. J Med Ent 3: 1-19.

Fairchild GB 1969. Notes on Neotropical Tabanidae XII. Classification and distribution, with keys to genera and subgenera. Arq Zool S Paulo 187: 199-255.

Fairchild GB 1971. Family Tabanidae. In N Papavero, $A$ Catalogue of the Diptera of the Americas South of the United States, Museu de Zoologia, São Paulo, Vol. 28, p. 1-163.

Fairchild GB, Burger JF 1994. A Catalog of the Tabanidae (Diptera) of the Americas South of the United States, Memoirs Amer Entomol Inst Associated Publishers 55, $249 \mathrm{pp}$.

Kröber O 1930. Die Pelecorhynchinae und Melpiinae Sudamerikas. (Dipteren, Tabanidae). Mitt Zool Mus Hamburg 44: 149-196.

Lutz A 1909. Tabaniden Brasiliens und einiger Nachbarstaaten. Zool Jahrb 4 (Suppl. 10): 619-692.

Mackerras IM 1960. The Tabanidae (Diptera) of Australia III. Subfamily Pangoniinae, Tribe Scionini and Supplement of Pangoniini. Austr J Zool 8: 1-152.

Ricardo G 1902. Further notes on the Pangoninae of the family Tabanidae in the British Museum collection. Ann \& Mag Nat Hist 77: 424-438.

Walker F 1850. Insecta Saundersiana, or characters of undescribed insects in the collection of W W Saunders. Diptera 1: 1-76.

Wiedemann CRW 1828. Aussereuropäische zweiflugelige Insekten, Vol. 1, 608 pp.

Wilkerson RC, Coscarón S 1984. A review of South American Scaptia (Pseudoscione) (Diptera: Tabanidae). J Econ Entomol 21: 213-236. 